\title{
Time trends analysis of statin prescription prevalence, therapy initiation, dose intensity, and utilization from the hospital information system of Jinshan Hospital, Shanghai (2012-2018)
}

Yujuan Liu ${ }^{1}$, Xiaoqun Lv ${ }^{1}$, Ning Xie ${ }^{2}$, Zhonghong Fang ${ }^{1}$, Weifang Ren ${ }^{1}$, Yuan Gong ${ }^{1}$, Yan Jin ${ }^{3^{*}}$ and Jun Zhang ${ }^{\text {* }^{*}}$

\begin{abstract}
Background: Statin remains a mainstay in the prevention and treatment of cardiovascular diseases. Statin utilization has evolved over time in many countries, but data on this topic from China are quite limited. This study aimed to investigate the changing trends of statins prescription, as well as detail the statin utilization through a successive longitudinal study.
\end{abstract}

Methods: The prescription database was established based on electronic health records retrieved from the hospital information system of Jinshan Hospital, Fudan University from January 2012 to December 2018 in Shanghai, China. The prescription rates and proportions of different statin types and doses among all patients were examined. Subanalyses were performed when stratifying the patients by age, gender, dose intensity, and preventative intervention.

Results: During the study period, a total of 51,083 patients, who were prescribed for statins, were included in this study (mean [SD] age, $59.78[ \pm 13.16]$ years; $53.60 \%$ male, $n=27,378$ ). The overall statins prescription rate in which patients increased from 2012 (1.24, 95\% Cl: 1.21-1.27\%) to 2018 (3.16, 95\% Cl: 3.11-3.20\%), $P<0.001$. Over 90\% of patients were given a moderate dose of statins. Patients with a history of coronary and cerebrovascular events (over 32\%) were more likely to be prescribed with statins for preventative intervention. Furthermore, our study has witnessed a significant rise in statin therapy in primary and secondary prevention.

Conclusions: In conclusion, statins were frequently prescribed and steadily increased over time in our study period. There were also changes in statin drug choices and dosages. A coordinated effort among the patient, clinical pharmacist, stakeholders and health system is still needed to improve statin utilization in clinical practice in the future.

Keywords: Statins, Prevalence, Cardiovascular disease, Initiation, Preventative intervention

\footnotetext{
*Correspondence: kokolo2000@163.com; zjhlj2006@163.com

${ }^{3}$ Shihua Community Health Service Center, Jinshan District, Shanghai 200540,

China

'Department of Clinical Pharmacy, Jinshan Hospital Affiliated to Fudan

University, Shanghai 201508, China

Full list of author information is available at the end of the article
}

C C The Author(s). 2020 Open Access This article is licensed under a Creative Commons Attribution 4.0 International License, which permits use, sharing, adaptation, distribution and reproduction in any medium or format, as long as you give appropriate credit to the original author(s) and the source, provide a link to the Creative Commons licence, and indicate if changes were made. The images or other third party material in this article are included in the article's Creative Commons licence, unless indicated otherwise in a credit line to the material. If material is not included in the article's Creative Commons licence and your intended use is not permitted by statutory regulation or exceeds the permitted use, you will need to obtain permission directly from the copyright holder. To view a copy of this licence, visit http://creativecommons.org/licenses/by/4.0/ The Creative Commons Public Domain Dedication waiver (http://creativecommons.org/publicdomain/zero/1.0/) applies to the data made available in this article, unless otherwise stated in a credit line to the data. 


\section{Background}

The incidence of cardiovascular diseases (CVD) continues to rise and has become the leading cause of mortality (responsible for above $40 \%$ of all deaths) in China in recent years [1]. Statins, the professional name of 3-hydroxy-3-methylglutaryl coenzyme A reductase inhibitors, have been proven to lower the morbidity and mortality of cardiovascular events and widely used in prevention in patients with CVD [2]. It is recommended as the most effective lipidlowering drug at present, which can not only effectively reduce total cholesterol (TC) but also low-density lipoprotein (LDL) [3-5].

Cholesterol plays a crucial role in the pathogenesis of coronary heart disease (CHD) and Atherosclerotic cardiovascular disease (ASCVD), and it has been a global consensus to prevent and control the cardiovascular risk of ASCVD by reducing blood LDL cholesterol (LDL-C) level [6]. The American College of Cardiology (ACC)/American Heart Association (AHA) 2013 guidelines (2013 ACC/AHA) cholesterol guidelines recommend that all patients with ASCVD should receive high-dose or moderate-dose statins therapy while ignoring lipid targets, and have recommended statin therapy to a specific group for primary and secondary prevention [7]. The 2016 European Society of Cardiology (ESC)/the European Atherosclerosis Society (EAS) (2016 ESC/EAC), the most widely used lipid management guideline, still targets lipid levels at different stages of disease activity before recommending statins [8]. Based on the 2007 Chinese Guidelines for the Management of Dyslipidemia in Adults, the 2016 Chinese guideline for the management of dyslipidemia in adults (referred to as "the new Guideline" hereafter) was released by Chinese Journal of Cardiology in 2016 formulated by a joint committee of multidisciplinary experts. It is not only in line with other important international guidelines but also has its own recommendations. It emphasizes the critical role of cholesterol on ASCVD. The new guidelines highlight the overall cardiovascular risk assessment, the use of LDL-C as the preferred intervention target (Class I recommendation, Level A evidence) and some other aspects (for more details, please refer to [9]). The introduction and popularization of the new guidelines will greatly increase the confidence of clinicians in statins utilization and contribute to more standardized use of statins in China.

Statins rank the most commonly prescribed medications in many countries, and general increase trends have been witnessed worldwide. In the United States (US), statin users in adults who reported using any statin observed a $79.8 \%$ increase from $17.9 \%$ (2002-2003) to 27.8\% (2012-2013) [10]. They also reported a steady increase among patients without ASCVD, those with diabetes and those with hyperlipidemia and not diabetes over the 12 years. From another study in the UK, prescription prevalence increased sharply from 1995 to 2013. Meanwhile, statin therapy initiation rates rose sharply from 1995 to 2006 [11]. In addition, the proportion of high-intensity statin increased from $16.5 \%$ in (2002-2003) to $20.4 \%$ (2012-2013) in the general adult population [10]. Similarly, prescription of high-intensity statins significantly increased, particularly, among patients with cerebrovascular accidents (CVA) [12] and coronary artery disease [2]. By contrast, high-intensity statins use remained low in Taiwan [13] and Hong Kong [14]. Although the 2013 ACC/AHA guideline recommends the initiation of high-intensity statin therapy in patients with ASCVD regardless of baseline low-density lipoprotein (LDL) cholesterol levels.

Over the past two decades, accumulating evidence has shown the real benefits of different statins in reducing the risk of cardiovascular events (including myocardial infarction, coronary heart death, and ischemic stroke). In addition to that, several large-scale clinical trials have consistently proven that statins could play a significant role in both primary and secondary prevention. These studies also expanded the scope of statin application from patients with ASCVD to primary prevention group and even more extensive populations. Recent studies indicated that cumulative exposure to lipids plays a critical causative role in the initiation and progression of atherosclerosis [15]. Patients who tend to be at risk for developing atherosclerosis will benefit most from statin therapy by the maintenance of the optimal lipid levels from early in life [16]. However, the clinical effect in the population at low risk of cardiovascular disease still needs further study.

Also, statins have been the most commonly prescribed drugs in China in recent decades. Currently, plenty of medicaments of statins have entered the market. Frequently used statins in China include lovastatin, simvastatin, pravastatin, fluvastatin, atorvastatin, rosuvastatin, and pitavastatin. A previous study has shown that the overall statins prescription rate in patients with a discharge diagnosis with ASCVD was 58.8\% in West China Hospital from 2008 to 2014. It has an average 10-20\% lower rate when compared with that in western or developed countries [17]. Except for a few studies $[11,13,14]$, little is known about the detailed utilization of statins. Thus, in this study, we will not only investigate the change trends of statins but also demonstrate statin prescription prevalence, therapy initiation, dose intensity, and its utilization in preventative interventions in a tertiary hospital of China for a successive 7 years. The result of this comprehensive study will contribute to form 
the general clinical practice in statin use and provide evidence-based guidelines in China.

\section{Methods}

\section{Data source and sample selection}

This study is a consecutive cross-sectional study based on longitudinal monitoring data analysis focusing on patients receiving any statin treatment from January 1 , 2012, to December 31, 2018. Data were retrieved from the hospital information system (HIS) of Jinshan hospital affiliated to Fudan University, which is the only thirdtier hospital in the catchment area. It has 1000 regular hospital beds. In 2016, the hospital has handled 1.47 million outpatient and emergency visits. The related information was withdrawn from patients receiving their first statin therapy during the study period. The prescription contains the medical card number, patient name, gender, age, diagnosis, generic name of statin and dosage. Different types of statins including atorvastatin, simvastatin, rosuvastatin, pravastatin, fluvastatin prescription were analyzed. We obtained the registered population, gender and age composition of Jinshan district from 2012 to 2018 through the statistical yearbook of Jinshan District, Shanghai.

\section{Inclusion/exclusion criteria}

Patients were deemed to be prescribed statins once when they received any types and dosages of statins. The exposure of statin-treated patients was manually examined by two reviewers. Only individuals aged 18 years or above were included in our study. Patients with a missing medical card number or an unknown date of birth or gender were excluded. We also excluded patients who changed their prescribed statins in a calendar year.

\section{Statin prescription rate}

Statin prescription data were retrieved from all prescriptions containing any dispensation of atorvastatin, fluvastatin, pravastatin, rosuvastatin or simvastatin. A statin user was considered and defined if they had at least one statin prescription dispensing in a given calendar year. The dose, intensity, and frequency of each drug were retrieved and analyzed.

Statin prescription rate included two measurements: total and new prescription rate. For the total prescription rate of a specific statin agent, we calculated the number of patients prescribed with a specific statin agent, then divided by the total number of statin users in the year. Similarly, we calculated the new prescription rate by referring to the previous study [13].

Statin therapy initiation rate and prescription prevalence We defined initiation of statin therapy if a patient, who was not on a statin during a 365-day washout period (new statin users), was prescribed any statin prescription before admission. The statin therapy initiation rate was calculated as previously described as the total number of new statin users per year divide by the annual population at risk [14]. Furthermore, we also analyzed the statin initiation rate according to gender, age group, statin intensity, and preventative intervention.

The statin prescription prevalence was estimated by using the total number of patients with any statin prescription during each calendar year as the numerator, while the annual total population in the hospital catchment area as the denominator. Prevalence was also stratified according to gender, age group and statin dose intensity. All statin prescriptions in this study were from 2012 to 2018. We took 2012 as the baseline to study the prescription prevalence rate of new statin users from 2013 to 2018.

\section{Statin dose intensity}

Statin dose intensity was defined as per the guidelines for the prevention and treatment of dyslipidemia in Chinese adults (2016) [18], ACC/AHA guideline on the treatment of blood cholesterol [7] and definition as previously described [13]. (1) low-intensity statins was defined as atorvastatin $<10 \mathrm{mg} /$ day, rosuvastatin $<5 \mathrm{mg}$ / day, simvastatin $<20 \mathrm{mg} /$ day, pravastatin $<40 \mathrm{mg} /$ day and fluvastatin $<80 \mathrm{mg} /$ day; (2) moderate-intensity statins was defined as $10 \mathrm{mg} /$ day $\leqq$ atorvastatin $<40 \mathrm{mg} /$ day, $5 \mathrm{mg} /$ day $\leqq$ rosuvastatin $<20 \mathrm{mg} /$ day, $20 \mathrm{mg}$ /day $\leqq$ simvastatin $<80 \mathrm{mg} /$ day, pravastatin $\geqq 40 \mathrm{mg} /$ day, and fluvastatin $\geqq 80 \mathrm{mg} /$ day; (3) high-intensity statins was defined as atorvastatin $\geqq 40 \mathrm{mg} /$ day, rosuvastatin $\geqq 20 \mathrm{mg} /$ day and simvastatin $\geqq 80 \mathrm{mg} /$ day.

\section{Primary and secondary prevention of cardiovascular disease}

Primary and secondary prevention have a major role in the fight against cardiovascular diseases. We defined primary and secondary prevention based on criteria of the China Cholesterol Education Program (CCEP) in 2014 and the Chinese guidelines for the prevention and treatment of dyslipidemia in adults in 2007 [19]. We also referred ICD-10 (International Classification of Diseases) diagnosis codes [20].

\section{Statistical analysis}

Statistical analysis was performed by the application of SAS (version 9.2). Baseline characteristics of patients were summarized using frequencies and proportions for categorical data. Continuous variables were expressed as mean \pm standard deviation. 95\% confidence intervals for the observed prevalence and initiation rates were calculated. Cochran-Armitage test for trend was applied to analyze overall estimates of statin prescription 
prevalence in consecutive years. Comparisons of the proportions were carried out using Pearson's chi-squared test, and continuous variables were compared using analysis of variance (ANOVA) or Student's $t$-test as appropriate. A $p$-value $<0.05$ was considered statistically significant for all analyses.

\section{Results}

\section{Patient demographics and statin prescription}

Overall, the total number of patients exposing to statin between January 1, 2012, to December 31, 2018, was 51, 083 with an average age of 59.78 years. The proportion of males reached up to $53.60 \%(n=27,378)$ of the overall population. The age band with a maximum number of patients was 35-59 years old, with a total of 23,006 patients accounting for $45.04 \%$, followed by age group 65-79 ( $n=14,842$, accounting for $29.05 \%)$. Patient demographics and statin therapies are described in Table 1 . We in total analyzed 279, 223 statin prescriptions during the study period. Rosuvastatin $(n=188,823$, $67.62 \%)$ was the highest-ranked statin in investigated patients, followed by atorvastatin $(n=45,974,16.47 \%)$ and simvastatin $(n=30,718,11.00 \%)$.

\section{Choice of statin and prescription rate}

The total prescription rate trend in the statin use between 2012 and 2018 was shown in Fig. 1. Rosuvastatin had an increase in its share of statin users from 2012 and 2016, from 58.23\% in 2012 (95\% CI: $57.02-59.44 \%$ ) to $78.22 \%$ in 2016 (95\% CI: $77.48-78.96 \%), p<0.001$. The prescription rate declined slightly from 2017 to

Table 1 Patient demographics of statin users and statin prescriptions from the hospital information system of Jinshan Hospital, Shanghai

\begin{tabular}{ll}
\hline Characteristics & Value (\%) \\
\hline Gender & \\
Male & $27,378(53.60)$ \\
Age & \\
18-34 years & $1679(3.29)$ \\
35-59years & $23,006(45.04)$ \\
60-64 years & $7971(15.60)$ \\
$65-79$ years & $14,842(29.05)$ \\
+80 years & $3585(7.02)$ \\
Average age & 59.78 \\
Total prescriptions & 279,223 \\
simvastatin & $30,718(11.00)$ \\
rosuvastatin & $188,823(67.62)$ \\
ravastatin & $9624(3.45)$ \\
atorvastatin & $45,974(16.47)$ \\
fluvastatin & $4084(1.46)$ \\
\hline
\end{tabular}

2018 (70.86, 95\% CI: 70.17-71.55\%). The prescribing rate of simvastatin decreased more than 14 times from $28.60 \%$ (95\% CI: $27.49-29.71 \%$ ) in 2012 to $2.74 \%$ (95\% CI: $2.49-2.99 \%)$ in 2018, $p<0.001$. However, the prescription rate of atorvastatin in 2012-2018 showed an overall upward trend, from 7.75\% (95\% CI: 7.09$8.41 \%$ ) in 2012 to $20.00 \%$ (95\% CI: $19.39-20.61 \%$ ) in $2018, p<0.001$. The prescribing rate of fluvastatin was relatively small and showed a downward trend. The prescribing rate of pravastatin in 2018 was $1.02 \%$ (95\% CI: $0.87-1.07 \%$ ). During the study period, the rate of pravastatin increased slightly, from $0.88 \%$ (95\% CI: $0.65-$ $1.10 \%$ ) in 2012 to $5.37 \%$ (95\% CI: $5.03-5.71 \%$ ) in 2018 , $p<0.001$.

We identified 47,924 new statin users between 2013 and 2018. The highest prescription rate of the annual use of statins in new users was rosuvastatin, with an increasing trend from 2013 to 2016 (69.87, 95\% CI: $68.68-71.06 \%$ in 2013 ; 80.54 , 95\% CI: $79.68-81.40 \%$ in 2016), and slightly decreased in 2017 and 2018, $p<0.001$ (Fig. 1). There was a significant downward trend in new statin users of simvastatin, and the prescription rate decreased from 11.07\% (95\% CI: 10.26 to $11.89 \%$ ) in 2013 to $1.84 \%$ (95\% CI: $1.59-2.09 \%$ ) in 2018 , roughly 6 times $(p<0.001)$. The prescription rate of atorvastatin showed an upward trend, from $14.56 \%$ (95\% CI: $13.65-15.48 \%$ ) in 2013 to $22.95 \%$ (95\% CI: $22.17-23.73 \%$ ) in 2018. The prescription rate of fluvastatin was relatively low and showed a downward trend in new statin users.

\section{Statin prescription prevalence}

Statin prescription prevalence has increased consistently from 2012 to 2018 (test for trend in proportions, $p<$ 0.001 ), which showed nearly a threefold in prevalence rate $(1.24$, 95\% CI: $1.21-1.27 \%$, in 2012 versus 3.16 , 95\% CI: $3.11-3.20 \%$, in 2018) as shown in Fig. 2a.

Gender- and age-stratified analysis showed that males tended to have a higher prevalence of statin than women each year (Fig. 2b). For the 65-79 age group, they had the highest statin prescription prevalence in every year of the study, and increased from $2012(2.88,95 \% \mathrm{CI}$ : 2.75-3.01\%) to 2018 (6.59, 95\% CI: 6.42-6.76\%) (Fig. 2c). A general increase in the prescription rate was observed for other age groups between 2012 and 2018 except for the 18-34 age group.

\section{Statin initiation rates}

Based on 47,924 new statin users, statin initiation rate consistently increased from $1.10 \%$ (95\% CI: $1.07-1.13 \%$ ) in 2013 to $2.15 \%$ (95\% CI: 2.11-2.19\%) in 2018 (Fig. 3a). The average age at therapy initiation increased from $59.12( \pm 13.31)$ to $60.63( \pm 12.87)$ years between 2013 and 2017 and changed steadily in $2018(60.53 \pm 12.89)$. 

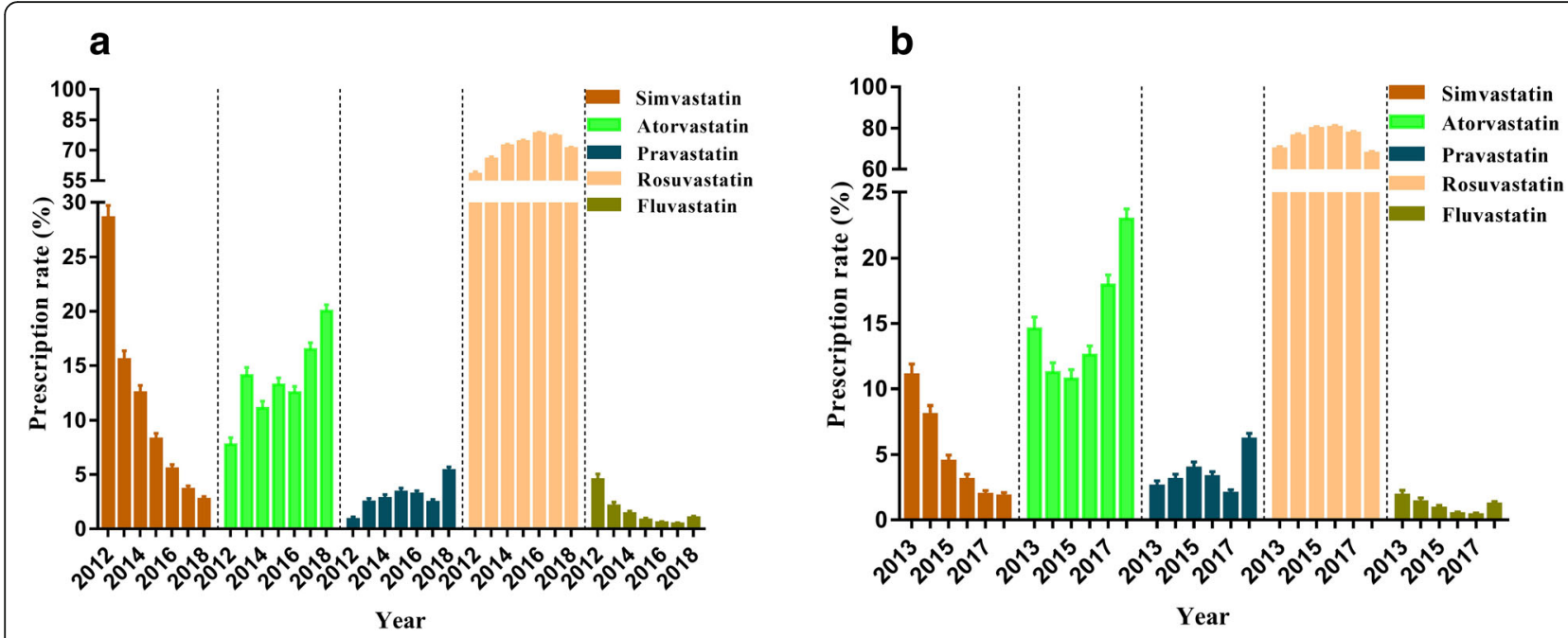

Fig. 1 Prescription rate of statins among total statin users (a) and new users (b) from the hospital information system of Jinshan Hospital, Shanghai between 2012 and 2018. The error bars represent the upper and lower bounds of the 95\% confidence intervals

Women were on average 3.78 years older than men at treatment initiation (Table 2). The average age of new users is lower than that of the general population, and there was a significant statistical difference, $p<$ 0.001. Among statin initiators, males have a higher initiation rate than females (Fig. 3b). When stratified according to age (Fig. 3c), there was a consistent initiation rate for new users in all age groups. There were evident rapid increases in initiation rates for 65-79 age group, which increased from 2.23\% (95\% CI: $2.12-2.34 \%$ ) to $4.15 \%$ (95\% CI: $4.02-4.29 \%$ ). The second higher initiation rates were among aged 60-64 and aged above 80 .

\section{Statin dose intensity analysis}

Most of the prescriptions had a moderate dose of statins. Thus, the prescription rate of moderate-intensity statins gradually increased from 90.64\% (95\% CI: 89.93-91.35\%) in 2012 to $99.59 \%$ (95\% CI: $99.50-$ $99.69 \%$ ) in 2018. The prescription rate of lowintensity statins decreased from $11.13 \%(95 \% \mathrm{CI}$ : $10.35-11.90 \%$ ) in 2012 to $0.04 \%$ in 2018 (95\% CI: $0.01-0.07 \%)$. The prescription rate of high-intensity in 2016 rose by up to $1.95 \%$ (95\% CI: $1.70-2.20 \%$ ), while decreased gradually and reached to $0.37 \%$ in 2018 (95\% CI: $0.28-0.46 \%$ ) (Fig. 4a). The new statin users were mainly prescribed with moderate-intensity therapy. The prescription rate increased gradually from 2012 to 2018. The low-intensity statin prescription rates continued to drop. The prescription rate of high-intensity statins first increased and then decreased (Fig. 4b).

\section{Primary and secondary prevention of cardiovascular disease}

A total of 32,147 (62.93\%) were taking statins for primary prevention, approximately 1.7 times of the number for secondary prevention. There was a higher percentage of use of statins among patients with hypertension, hyperlipidemia, and cerebrovascular disease (Table 3). Primary prevention occurred mainly in the age group below 60 when stratified by age. Both of the prescription rates of primary and secondary prevention increased among the 60-64 age group, but the rate of secondary prevention increased more rapidly. In 2018 , the prescription rate of primary prevention is basically on par with secondary prevention, which was $2.37 \%$ (95\% CI: $2.24-2.50 \%$ ) and $2.58 \%$ (95\% CI: $2.45-2.71 \%$ ) respectively. The prescription rate of secondary prevention increased from $1.01 \%$ (95\% CI: 0.94-1.09\%) in 2012 to $3.59 \%$ (95\% CI: $3.46-3.71 \%$ ) in 2018 in the 65-79 age group (Fig. 5a). The prescription rate of primary prevention was similar to that in secondary prevention in the age group above 80 in 2012, however, the prescription rate of secondary prevention increased rapidly in 2018 (3.60, 95\% CI: 3.37-3.83\%). The prescription rate for new statin user prevention had a parallel trend with the total patient (Fig. 5b).

The three most prescribed statin drugs were simvastatin, atorvastatin and rosuvastatin (Fig. 6). The initiation rate of simvastatin for primary prevention was higher than that for secondary prevention between 2013 and 2018. The initiation rate of atorvastatin for secondary prevention was slightly higher than that for primary prevention between 2013 and 2017. However, the initiation rate of atorvastatin for secondary prevention $(0.31,95 \% \mathrm{CI}: 0.29-0.32 \%)$ was nearly two 


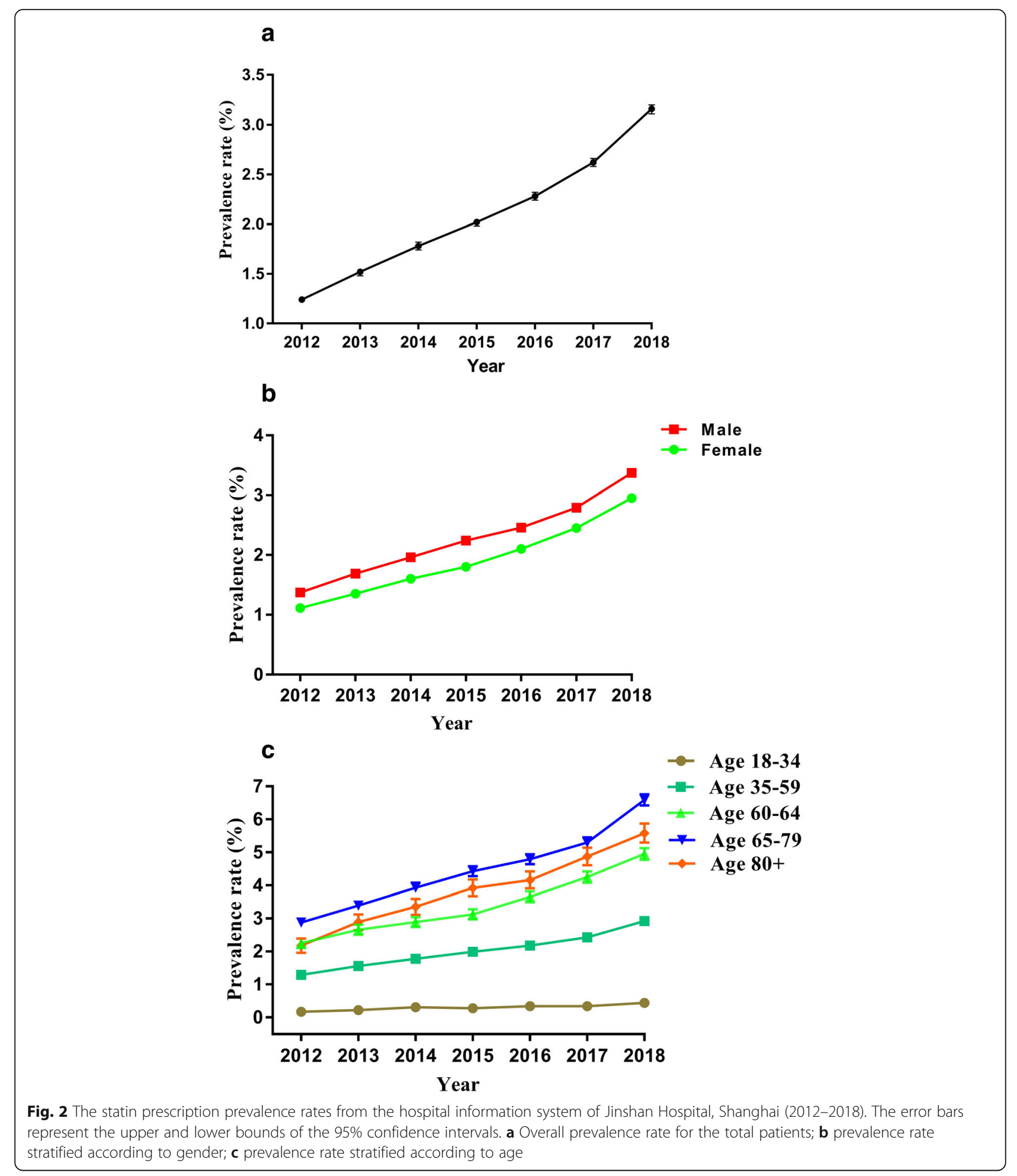

folds than that for primary prevention $(0.19,95 \% \mathrm{CI}$ : $0.17-0.20 \%)$ in 2018 . The initiation rate of rosuvastatin for primary prevention was higher than that for secondary prevention between 2013 and 2016, but vice versa since 2017 .

\section{Discussion}

This work is the most recent and comprehensive study on detailed statin utilization among patients using a large amount of important historical data of our hospital records. The results enable us to have detained 
a

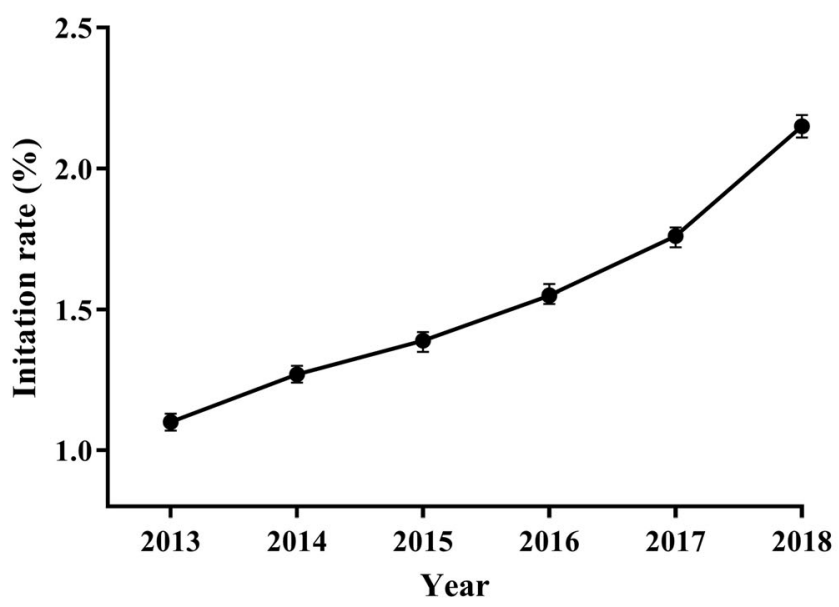

b

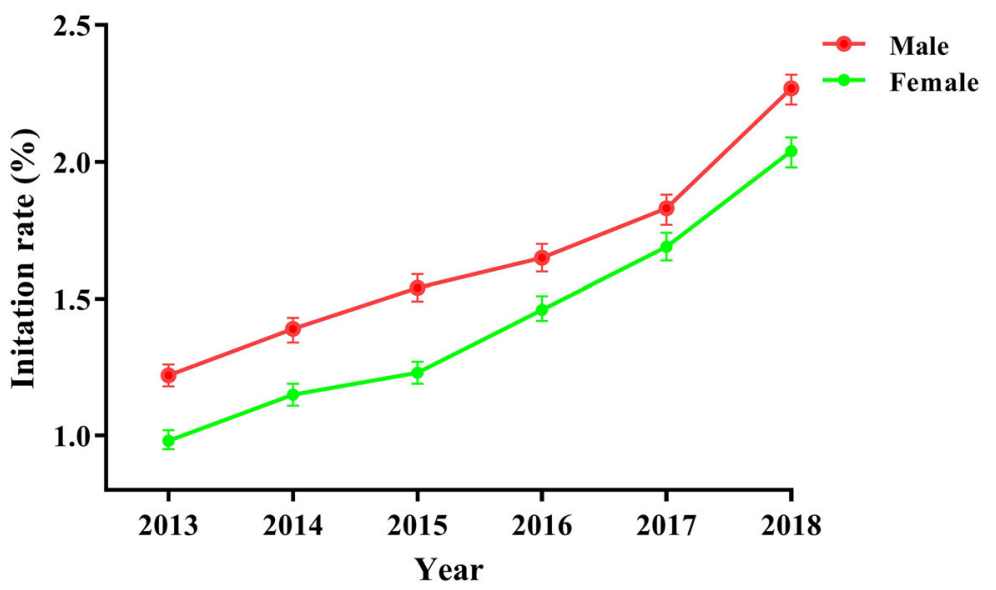

C

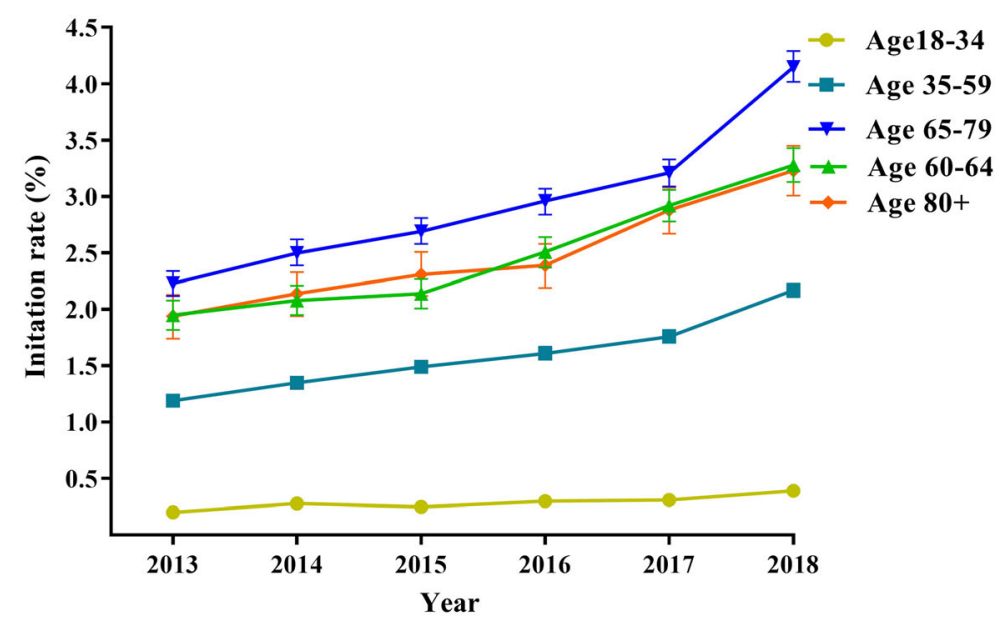

Fig. 3 The new statin user's initiation rates from the hospital information system of Jinshan Hospital, Shanghai (2013-2018). The error bars represent the upper and lower bounds of the $95 \%$ confidence intervals. a Overall initiation rate for the new users; $\mathbf{b}$ initiation rate stratified according to gender; $\mathbf{c}$ initiation rate stratified according to age 
Table 2 The average of new statin users between 2013 and 2018 from the hospital information system of Jinshan Hospital, Shanghai

\begin{tabular}{lllll}
\hline Year & Number of new users(\%) & Average age $($ mean \pm SD) & Male average age $($ mean \pm SD) & Female average age $($ mean \pm SD) \\
\hline 2013 & $5699(72.67 \%)$ & $59.12 \pm 13.31$ & $57.23 \pm 13.55$ & $61.43 \pm 12.64$ \\
2014 & $6567(71.24 \%)$ & $59.10 \pm 13.60$ & $57.15 \pm 14.11$ & $61.43 \pm 12.57$ \\
2015 & $7179(68.70 \%)$ & $59.58 \pm 13.39$ & $57.49 \pm 13.84$ & $62.16 \pm 12.35$ \\
2016 & $8084(68.14 \%)$ & $59.95 \pm 12.95$ & $58.38 \pm 13.41$ & $61.69 \pm 12.18$ \\
2017 & $9176(67.01 \%)$ & $60.63 \pm 12.87$ & $59.18 \pm 13.60$ & $62.19 \pm 11.85$ \\
2018 & $11,216(68.05 \%)$ & $60.53 \pm 12.89$ & $58.96 \pm 13.49$ & $62.22 \pm 11.99$ \\
\hline
\end{tabular}

understanding of statin prescription prevalence, therapy initiation, dose intensity, and utilization in the preventative intervention. We found that the statin prescription prevalence and initiation rate generally increased from 2012 to 2018, with most patients receiving moderateintensity statins. Statins for primary prevention were more than that for secondary prevention. Patients with a medical history of hypertension, hyperlipidemia, and cerebrovascular events were more likely to be prescribed with statins for preventative intervention.

Statin use increased substantially in the last decade. Our finding is in line with previous studies in the United Kingdom (UK) [11], Taiwan [13], Belgium [21] and Hong Kong [14]. We speculate that the main reason may be as follow. Firstly, in recent years, the incidence of CVD continues to rise and has become the leading cause of mortality (above 40\%) in China [1, 22]. Meanwhile, accumulating evidence has emerged to show the benefits of statins in the prevention of CVD, which facilitate the widespread use of statins. Secondly, the role of statins for secondary CVD prevention has been well established in several large randomized clinical trials. There has been a tendency in guidelines to offer benefits to a broad range of patients for primary prevention of CVD during the past decade [23]. However, the overall prevalence of statin use is lower from $2012(1.24,95 \%$ CI: $1.21-1.27 \%)$ to 2018 (3.16, 95\% CI: $3.11-3.20 \%)$ in our study when compared with other studies. For instance, Joseph et al. reported the statin prevalence increased from 2004 (1.82, 95\% CI: $1.78-1.86 \%)$ to 2015 (8.68, 95\% CI: 8.60-8.75\%) in Hong Kong, which is still lower than the prescription prevalence in the UK in 2007 (calculated as 96.53 per 1000 person-years) [11], and even lower than the 2003-2004 (11, 95\% CI: 9.6$12 \%)$ and 2011-2012 (17, 95\% CI: 15-19\%) prevalence estimate from the US reported by Kantor et al. [24]. So, although the statin prescription prevalence was nearly doubled during the study period, the overall statins

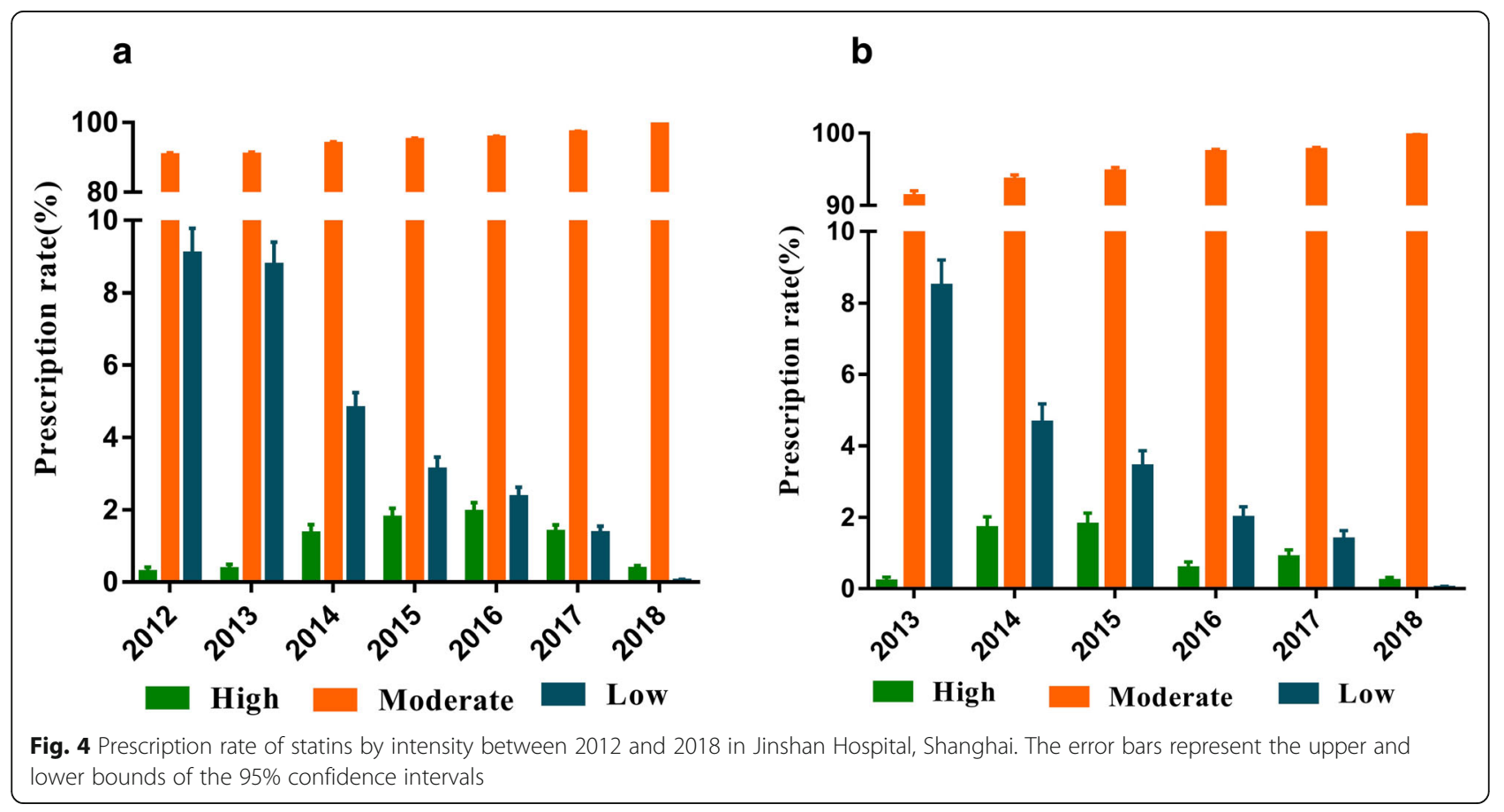


Table 3 The prevention status characteristics of statin users and prescription in Jinshan Hospital, Shanghai

\begin{tabular}{ll}
\hline Cardiovascular prevention status & Value(\%) \\
\hline Primary prevention & $32,147(62.93)$ \\
Secondary prevention & $18,936(37.07)$ \\
Medical history & \\
Cerebrovascular disease & $10,095(21.68)$ \\
Coronary artery disease & $5461(10.69)$ \\
Peripheral artery disease & $2622(5.13)$ \\
Percutaneous coronary intervention & $471(0.92)$ \\
Hypertension & $14,796(28.96)$ \\
Diabetes & $5709(11.18)$ \\
Hyperlipidemia & $12,394(24.26)$ \\
Renal disease & $2042(4.00)$ \\
\hline
\end{tabular}

prescription rate still could not catch up that in developed countries and regions.

Besides, our study showed that the statin prescription initiation rate increased steadily and doubled in 2018. Similar patterns were observed in other studies. For instance, in Hong Kong, statin initiation rates consistently rose from $0.44 \%$ in 2004 to $1.23 \%$ in 2013 [25]. Statin therapy initiation rates in the UK increased sharply from 1995 to 2006 [11]. Another study, which was conducted in Taiwan, the initiation rate has grown from $0.6 \%$ in 2002 to $1.8 \%$ in 2011 [13]. Nevertheless, declined trends in initiation rates were observed both in Hong Kong in 2014 and 2015 and the UK in 2006. However, we did not notice such a peak in statin therapy initiation in our study, likely because of the gap in the use of statins, lack of awareness, concerns about statin adverse effects, the burden of medical cost and physician-related factors. For example, in a study investigated the change trends of statins prescription at discharge among patients with ASCVD in one of the top-ranked China hospitals, the authors found that over $40 \%$ of patients with ASCVD were not prescribed statins when they were discharged from hospital [26]. Although, the past several years have witnessed increasing trends of statins prescription rates. Given both the low statin prescription prevalence and initiation rate, these shreds of evidence reflect the overall statin utilization rates are sub-optimal in real-world practice in China.

In the present study, we also observed a shift in statin drug choices. The most commonly used statin was rosuvastatin in our study period (2012-2018). This finding contrasts with other study results, for example, simvastatin was consistently the most prescribed statin in Hong Kong between 2004 and 2015 [14]. Atorvastatin had the highest prescription rates among new statin users throughout the study period (2002-2011) in Taiwan [13]. Interestingly, atorvastatin, simvastatin, and rosuvastatin were the most commonly prescribed statins in Asian countries and Norway [27]. Rosuvastatin had rapid annual growth in the proportion of statin users since it entered the global market in the 2000s. Prescription rates of pravastatin and fluvastatin remained relatively low. However, in recent years, we found policymakers have played a critical role in statin choice. Some European countries planned to promote prescribing of generically available statins to contain expenditure on health care. For instance, the Netherlands chose simvastatin as the reference drug to reduce costs [6]. An endorsed recommendation has also promoted a switch from atorvastatin 10 or $20 \mathrm{mg} /$ day to simvastatin $40 \mathrm{mg} /$ day or pravastatin $40 \mathrm{mg} /$ day in the UK [28]. Furthermore, Reimbursement policies have compelled physicians to alter their statin prescription in Finland [29], Italy [30], Norway [31], Germany [32] and Austria [33]. In clinical practice, Heintjes et al. suggested the choice of statin should be based on baseline cholesterol levels to meet the reduction in it and to adapt if failed, especially in high-risk patients [25]. Therefore, as to how to choose, except for objective factors, many other factors should be taken into account, including patients' disease conditions, cost, adverse effects, the efficacy and dose intensity of statin [3, 34-38].

Although the 2013 ACC/AHA recommend highintensity statins for adults with ASCVD [39] and prescribing rate and initiation of high-intensity statin increased in the US after release [10, 40, 41], use of highintensity statins remained low (under $2.1 \%$ ) in Taiwan [13]. Also, there was only a little increase in the prescription prevalence of high-intensity statins from 2004 (0.05, 95\% CI: $0.05-0.06 \%)$ to 2015 (0.42, 95\% CI: 0.40 $0.44 \%)$ [14] in Hong Kong. In our study, the peak prescription rate of high-intensity was 1.95\% (95\% CI: $1.70-2.20 \%)$ in 2015 and decreased gradually since then. In contrast, there was a consistent annual increase in the prescription rate of moderate-intensity statins. Also, Zhang et al. indicated that moderate-intensity statins could result in meaningful reductions in cardiovascular events [42]. More importantly, the 2016 Chinese guideline emphasized that most patients in China do not need and cannot tolerate the high-intensity high-dose statin treatment recommended by ACC/AHA, and it is clearly proposed that the low to moderate-intensity statin is more suitable for Chinese. Therefore, although some pharmacokinetic studies have demonstrated that rosuvastatin of multiple doses $(5,10$, and $20 \mathrm{mg})$ was generally well tolerated in healthy Chinese volunteers [43]. However, in clinical practice, high-intensity statins are prescribed to a few patients.

There is increasing evidence supporting statin use for primary and secondary prevention of CVD [7, 11, 25]. In the recent past, our study has a witnessed significant rise 


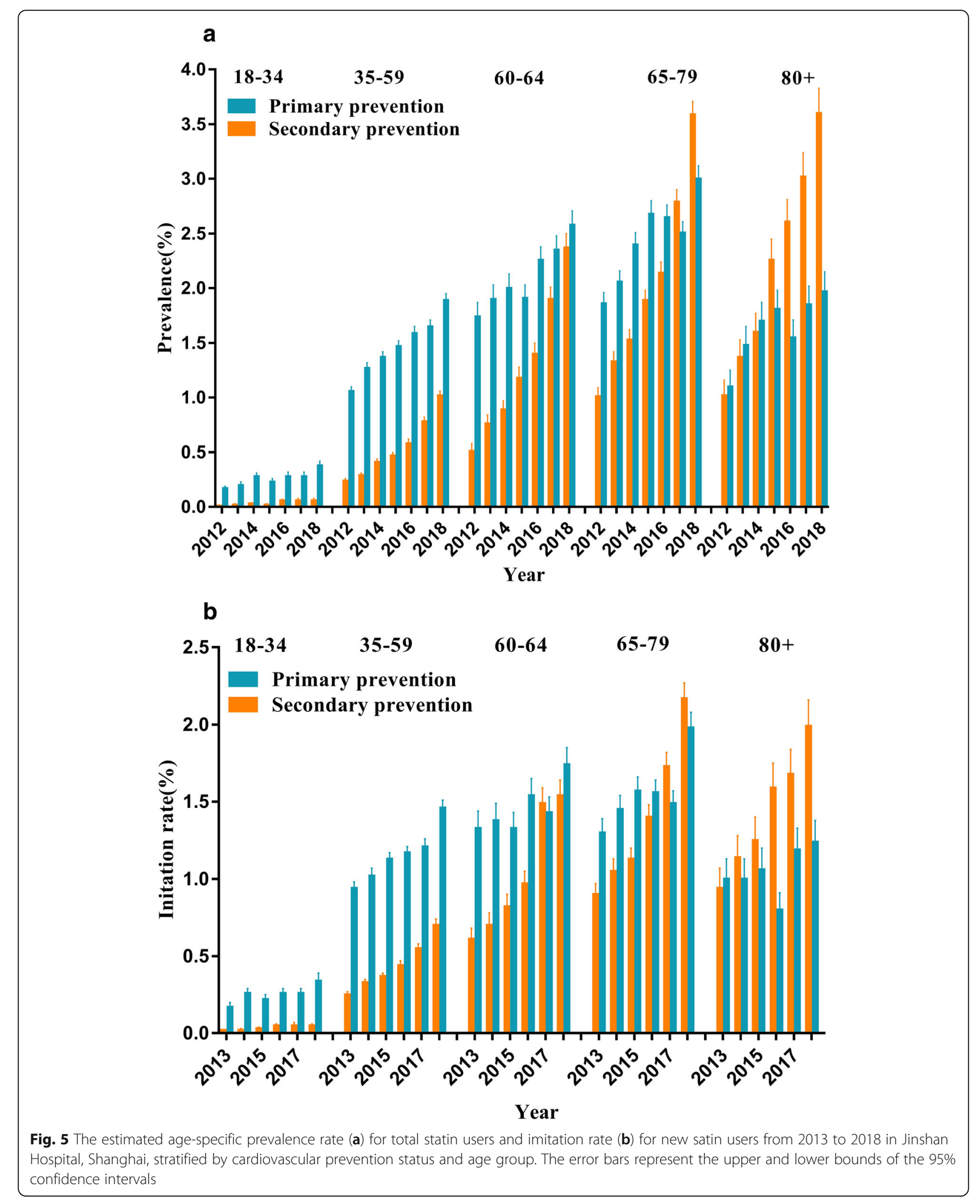




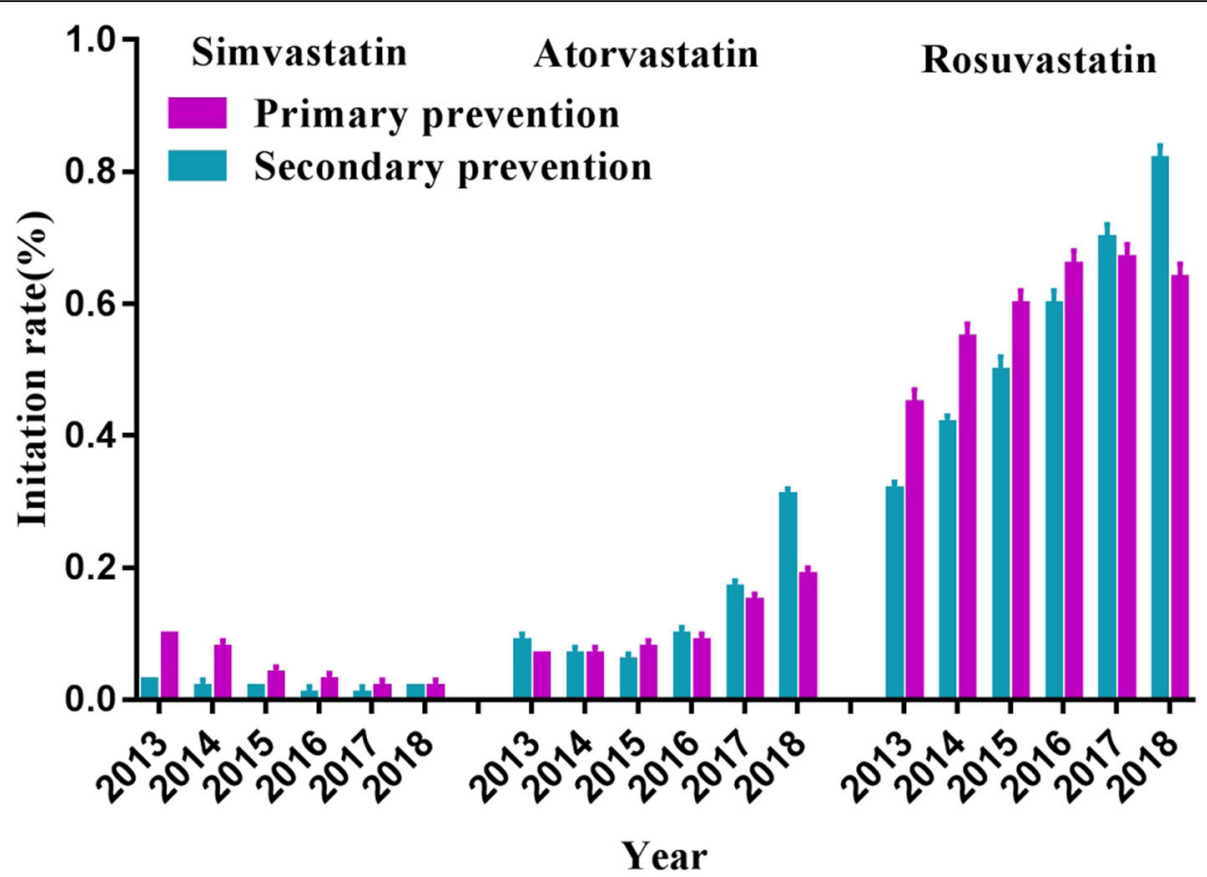

Fig. 6 The initiation rates of new statin users stratified by simvastatin, atorvastatin and rosuvastatin from 2013 to 2018 in Jinshan Hospital, Shanghai. The error bars represent the upper and lower bounds of the $95 \%$ confidence intervals

in statin therapy in primary and secondary prevention. Three-fifths $(62.93 \%)$ of the patients received statin therapy in primary prevention during the study period. However, the clinical benefits of statin use for primary and secondary prevention remain controversial, particularly in the elder population. A pharmacoepidemiological study in Italy revealed that although most of the patients received statin therapy in primary prevention, whereas the benefits of statins are documented mostly for patients in secondary prevention [25]. Saudi Arabia has witnessed a significant rise in CVD-related deaths in spite of the widespread use of statins in primary prevention. They also pointed out that the 2013 ACC/AHA guidelines may have overemphasized the statin therapy but without considering lipid targets which would lead to the inclusion of a large population for primary prevention with statins. Furthermore, this would cause overtreatment and potentially increase the incidences of statin-associated side effects and intolerance [8]. In addition, a statin prescription prevalence study reflects that the elderly population does not necessarily get the benefit from statin treatment for primary prevention of CVD [14]. Hence, the 2016 Chinese guideline still targets lipid levels at different stages of disease activity before recommending statins to draw guidance on the primary prevention of CVD. These findings strengthen the need to direct physicians and patients to the rational drug use of statins in the preventative intervention.
This work is the most recent and comprehensive study on statin utilization among patients using a large database of third-tier hospital. However, there are several limitations to this study. Our sample does not include data from the community hospitals and private healthcare system although the number of patients is estimated to be relatively small. Further, we would miss some samples in our estimates who may buy statins over the counter after their first visit to the hospital. A clear strength of this study is a continuous observational study with a large sample size and which reflects the local population and allows us to make an informed and comprehensive assessment of prescription prevalence, therapy initiation, dose intensity, and utilization in the preventative intervention.

\section{Conclusion}

In conclusion, prescription prevalence and initiation generally increased from 2012 to 2018, with most patients receiving moderate-intensity statins. In recent years, males appear to have been prescribed statins at higher rates than females. However, the overall statin prescription rate in patients was lower in China when compared with other studies. The uptake of statins for both the primary and secondary prevention of CVD has increased greatly over time, in particular, in the elder group. The choice of statin should be based on patients' actual conditions, the efficacy of statin, adverse effects and consideration to the cost performance. A 
coordinated effort among the patient, clinical pharmacist, stakeholders, and health system is still needed to improve statin utilization.

\section{Abbreviations}

CVD: Cardiovascular disease; TC: Total cholesterol; CHD: Coronary heart disease; ACC/AHA: American College of Cardiology /American Heart Association; ESC/EAS: European Society of Cardiology /the European atherosclerosis society; CVA: Cerebrovascular accident; LDL: Low-density lipoprotein; HIS: Hospital information system; CCEP: China cholesterol education program; ICD: International classification of diseases

\section{Acknowledgments}

We thank Dr. Xinyu Feng from China CDC for the management of data and analysis.

\section{Authors' contributions}

YJ.L and J. Z conceived and designed the study. YJ. L and Y. J analyzed the data and drafted the manuscript. YJ. L XQ. L, N. X, ZH. F, WF. R, Y. G and Y. J collected and organized the patient data from the patient files. J. Z critically revised the manuscript. All authors read and approved the final manuscript.

\section{Funding}

The work was funded by the Health Commission of Jinshan District, Shanghai (JSKJ-KTMS-2019-17) and "Qi Hang" Project of Jinshan Hospital, Fudan University (2018-JSYYQH-05). The funding sources had no involvement in study design; in the collection, analysis and interpretation of data; in the writing of the report; or in the decision to submit the article for publication

\section{Availability of data and materials}

The data that support the findings of this study are available from the corresponding author upon reasonable request.

\section{Ethics approval and consent to participate}

All procedures performed in the present study were in line with the Ethics Committee of Jinshan Hospital. We declared that the study protocols were approved by the Ethics Committee of Jinshan Hospital.

The present study retrospectively analyzed data abstracted from the hospital information system of Jinshan Hospital without interventions or disruptions to patients' lives, and no direct human participants were involved, thus informed consent was not required and waived by the Ethics Committee.

\section{Consent for publication}

Not applicable.

\section{Competing interests}

The authors declare that they have no competing interests.

\section{Author details}

'Department of Clinical Pharmacy, Jinshan Hospital Affiliated to Fudan University, Shanghai 201508, China. ${ }^{2}$ Department of Clinical Pharmacy, Zhongshan Hospital Qingpu Branch Affiliated to Fudan University, Shanghai 201799, China. ${ }^{3}$ Shihua Community Health Service Center, Jinshan District, Shanghai 200540, China.

Received: 20 January 2020 Accepted: 12 April 2020

Published online: 25 April 2020

\section{References}

1. Sun W, Zhou Y, Zhang Z, Cao L, Chen W. The Trends in Cardiovascular Diseases and Respiratory Diseases Mortality in Urban and Rural China, 19902015. Int J Environ Res Public Health. 2017;14(11):1391. https://doi.org/10. 3390/ijerph14111391.

2. Anderson JL, Knowlton KU, May HT, Bair TL, Armstrong SO, Lappe DL, Muhlestein JB. Temporal changes in statin prescription and intensity at discharge and impact on outcomes in patients with newly diagnosed atherosclerotic cardiovascular disease-Real-world experience within a large integrated health care system: The IMPRES study. J Clin Lipidol. 2018;12(4): 1008-18 e1001.
3. Hirsh BJ, Smilowitz NR, Rosenson RS, Fuster V, Sperling LS. Utilization of and adherence to guideline-recommended lipid-lowering therapy after acute coronary syndrome: opportunities for improvement. J Am Coll Cardiol. 2015; 66(2):184-92.

4. Tungsubutra W, Phongtuntakul B. Achievement of LDL-cholesterol goal with statins after an st segment elevation myocardial infarction. J Med Assoc Thail. 2015;98(2):129-36.

5. Zhao SP. Amendment of the low-density lipoprotein cholesterol target in the 'Chinese guidelines for the prevention and treatment of adult dyslipidemia': opinion. Chron Dis Transl Med. 2016;2(1):7-9.

6. Heintjes EM, Penning-van Beest FJ, Plat AW, Meerding WJ, Webb K, Sturkenboom MC, Herings RM. Cholesterol level goal attainment with statins: clinical management guideline recommendations versus management in actual clinical practice. Pharmacotherapy. 2012;32(7):631-41.

7. Stone NJ, Robinson JG, Lichtenstein AH, Bairey Merz CN, Blum CB, Eckel RH, et al. 2013 ACC/AHA guideline on the treatment of blood cholesterol to reduce atherosclerotic cardiovascular risk in adults: a report of the American College of Cardiology/American Heart Association task force on practice guidelines. Circulation. 2014;129(25 Suppl 2):S1-45.

8. Mahmood D, Jahan K, Habibullah K. Primary prevention with statins in cardiovascular diseases: a Saudi Arabian perspective. J Saudi Heart Assoc. 2015;27(3):179-91

9. Zhu JR, Gao RL, Zhao SP, Guoping LU, Zhao D, Jianjun LI, et al. 2016 Chinese guidelines for the management of dyslipidemia in adults. J Geriatr Cardiol Jgc. 2018;15(1):1-29.

10. Salami JA, Warraich H, Valero-Elizondo J, Spatz ES, Desai NR, Rana JS, et al. National Trends in statin use and expenditures in the US adult population from 2002 to 2013: insights from the medical expenditure panel survey. JAMA Cardiol. 2017;2(1):56-65.

11. O'Keeffe AG, Nazareth I, Petersen I. Time trends in the prescription of statins for the primary prevention of cardiovascular disease in the United Kingdom: a cohort study using the health improvement network primary care data. Clin Epidemiol. 2016;8:123-32.

12. Valentino M, Al Danaf J, Panakos A, Ragupathi L, Duffy D, Whellan D. Impact of the. American College of Cardiology/American Heart Association cholesterol guidelines on the prescription of high-intensity statins in patients hospitalized for acute coronary syndrome or stroke. Am Heart J. 2013;2016(181):130-6.

13. Hsieh HC, Hsu JC, Lu CY. 10-year trends in statin utilization in Taiwan: a retrospective study using Taiwan's National Health Insurance Research Database. BMJ Open. 2017;7(5):e014150.

14. Blais JE, Chan EW, Law SWY, Mok MT, Huang D, Wong ICK, Siu CW. Trends in statin prescription prevalence, initiation, and dosing: Hong Kong, 20042015. Atherosclerosis. 2019;280:174-82.

15. Lee H, Park JB, Hwang IC, Yoon YE, Park HE, Choi SY, et al. Association of four lipid components with mortality, myocardial infarction, and stroke in statin-naive young adults: a nationwide cohort study. Eur J Prev Cardiol. 2020:2047487319898571.

16. Lozano P, Henrikson NB, Morrison CC, Dunn J, Nguyen M, Blasi P, Whitlock EP. U.S. Preventive Services Task Force Evidence Syntheses, formerly Systematic Evidence Reviews. In: Lipid Screening in Childhood for Detection of Multifactorial Dyslipidemia: A Systematic Evidence Review for the US Preventive Services Task Force. edn. Rockville (MD): Agency for Healthcare Research and Quality (US); 2016.

17. Harrison TN, Scott RD, Cheetham TC, Chang SC, Hsu JY, Wei R, et al. Trends in statin use 2009-2015 in a large integrated health system: pre- and Post2013 ACC/AHA guideline on treatment of blood cholesterol. Cardiovasc Drugs Ther. 2018;32(4):397-404.

18. Joint Committee for Developing Chinese guidelines on Prevention and Treatment of Dyslipidemia in Adults. [Chinese guidelines on prevention and treatment of dyslipidemia in adults (2016 Revised version)]. Chin J Circ. 2016;16(10):15-35

19. Li X, Xu Y, Li J, Hu D. The gender differences in baseline characteristics and statin intervention among outpatients with coronary heart disease in China: the China cholesterol education program. Clin Cardiol. 2009; 32(6):308-14

20. Quan H, Sundararajan V, Halfon P, Fong A, Burnand B, Luthi J-C, et al. Coding algorithms for defining comorbidities in ICD-9-CM and ICD-10 administrative data. Med Care. 2005;43(11):1130-9.

21. Laleman N, Henrard S, van den Akker M, Goderis G, Buntinx F, Van Pottelbergh $G$, Vaes $B$. Time trends in statin use and incidence of recurrent 
cardiovascular events in secondary prevention between 1999 and 2013: a registry-based study. BMC Cardiovasc Disord. 2018;18(1):209.

22. Weiwei $C$, Runlin G, Lisheng L, Zhu M, Wang W, Wang Y. China cardiovascular disease report 2017: a summary. Chin J Circ. 2018;1:1-8.

23. Brown F, Singer A, Katz A, Konrad G. Statin-prescribing trends for primary and secondary prevention of cardiovascular disease. Can Fam Physician. 2017;63(11):e495-503.

24. Kantor ED, Rehm CD, Haas JS, Chan AT, Giovannucci EL. Trends in prescription drug use among adults in the United States from 1999-2012. J Am Med Assoc. 2015;314(17):1818.

25. Tomé-Carneiro J, Gonzálvez M, Larrosa M, Yáñez-Gascón MJ, García-Almagro FJ, Ruiz-Ros JA, Tomás-Barberán FA, García-Conesa MT, Espín JC. Resveratrol in primary and secondary prevention of cardiovascular disease: a dietary and clinical perspective. Ann N Y Acad Sci. 2013;1290(1):37-51.

26. Huang BT, Peng Y, Huang FY, Xia TL, Gui YY, Liao YB, et al. Trends in prescribing rate of statins at discharge and modifiable factors in patients with atherosclerotic cardiovascular disease. Intern Emerg Med. 2017;12(8): $1121-9$.

27. Hartz I, Sakshaug S, Furu K, Engeland A, Eggen AE, Njolstad I, Skurtveit S. Aspects of statin prescribing in Norwegian counties with high, average and low statin consumption - an individual-level prescription database study. BMC Clin Pharmacol. 2007;7:14

28. Moon JC, Bogle RG. Switching statins. BMJ. 2006;332(7554):1344-5.

29. Martikainen JE, Saastamoinen LK, Korhonen MJ, Enlund H, Helin-Salmivaara A. Impact of restricted reimbursement on the use of statins in Finland: a register-based study. Med Care. 2010;48(9):761-6.

30. Damiani G, Federico B, Anselmi A, Silvestrini G, lodice L, Navarra P, Cas RD, Raschetti R, Ricciardi W. The impact of Regional co-payment and National reimbursement criteria on statins use in Italy: an interrupted time-series analysis. BMC Health Serv Res. 2014;14(1):6-6.

31. Sakshaug S, Furu KO, Ronning M, Skurtveit S. Switching statins in Norway after new reimbursement policy: a nationwide prescription study. Br J Clin Pharmacol. 2010;64(4):476-81.

32. Gitt AK, Juenger C, Smolka W, Wood D, Kastelein J. Impact of a budgetrestrictive (Germany) versus an incentive-driven (UK) reimbursement system on LDL-goal-achievement in statin-treated patients for secondary prevention: results of DYSIS. Eur Heart J. 2013;34(suppl 1):3689.

33. Godman B, Burkhardt T, Bucsics A, Wettermark B, Wieninger P. Impact of recent reforms in Austria on utilization and expenditure of PPIs and lipidlowering drugs: implications for the future. Expert Rev Pharmacoecon Outcomes Res. 2009;9(5):475

34. Virani SS, Steinberg L, Murray T, Negi S, Nambi V, Woodard LD, Bozkurt B, Petersen LA, Ballantyne CM. Barriers to non-HDL cholesterol goal attainment by providers. Am J Med. 2011;124(9):876-80 e872.

35. Vijayakrishnan R, Kalyatanda G, Srinivasan I, Abraham GM. Compliance with the adult treatment panel III guidelines for hyperlipidemia in a resident-run ambulatory clinic: a retrospective data analysis. J Clin Lipidol. 2013;7(1):43-7.

36. Rosenson RS, Kent ST, Brown TM, Farkouh ME, Levitan EB, Yun $\mathrm{H}$, et al. Underutilization of high-intensity statin therapy after hospitalization for CoronaryHeart disease. J Am Coll Cardiol. 2015;65(3):270-7.

37. Jamé S, Wittenberg E, Potter MB, Fleischmann KE. The new lipid guidelines: what do primary care clinicians think? Am J Med. 2015;128(8):914.e915-0.

38. Elisabeth $A B$, Denig P, Vliet TV, Dekker JH. Reasons of general practitioners for not prescribing lipid-lowering medication to patients with diabetes: a qualitative study. BMC Fam Pract. 2009;10(1):24.

39. Huang Q, Grabner M, Sanchez RJ, Willey VJ, Cziraky MJ, Palli SR, Power TP. Clinical characteristics and unmet need among patients with atherosclerotic cardiovascular disease stratified by statin use. Am Health Drug Benefits. 2016:9(8):434-44.

40. Olufade T, Zhou S, Anzalone D, Kern DM, Tunceli O, Cziraky MJ, Willey VJ. Initiation Patterns of Statins in the 2 Years After Release of the 2013 American College of Cardiology/American Heart Association (ACC/AHA) cholesterol management guideline in a large US health plan. J Am Heart Assoc. 2017;6(5):e005205. https://doi.org/10.1161/JAHA.116.005205.

41. Zupec JF, Marrs JC, Saseen JJ. Evaluation of statin prescribing for secondary prevention in primary care following new guideline recommendations. Ann Pharmacother. 2016;50(1):17-21.
42. Zhang H, Plutzky J, Shubina M, Turchin A. Risk factors for lack of statin therapy in patients with diabetes and coronary artery disease. J Clin Lipidol. 2016;10(6):1406-13.

43. Li XN, Xu HR, Chen WL, Chu NN, Zhu JR. Pharmacokinetics of rosuvastatin in healthy Chinese volunteers living in China: a randomized, open-label, ascending single- and multiple-dose study. Clin Ther. 2010;32(3):575-87.

\section{Publisher's Note}

Springer Nature remains neutral with regard to jurisdictional claims in published maps and institutional affiliations.

\section{Ready to submit your research? Choose BMC and benefit from:}

- fast, convenient online submission

- thorough peer review by experienced researchers in your field

- rapid publication on acceptance

- support for research data, including large and complex data types

- gold Open Access which fosters wider collaboration and increased citations

- maximum visibility for your research: over $100 \mathrm{M}$ website views per year

At $\mathrm{BMC}$, research is always in progress.

Learn more biomedcentral.com/submissions 